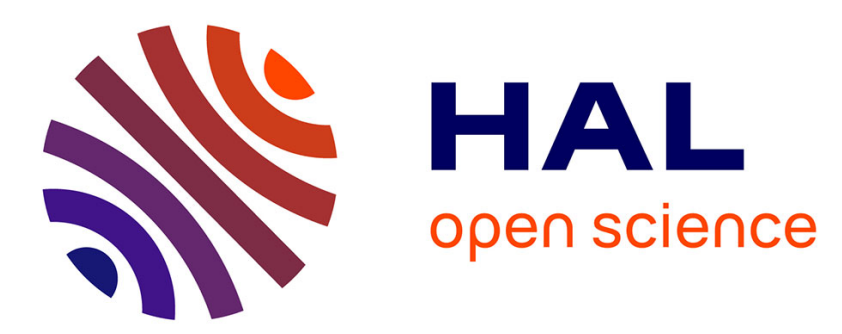

\title{
Evaluation of ERS Scatterometer soil moisture products over a half-degree region in Southwestern France
}

Thierry Pellarin, Jean-Christophe Calvet, Wolfgang Wagner

\section{To cite this version:}

Thierry Pellarin, Jean-Christophe Calvet, Wolfgang Wagner. Evaluation of ERS Scatterometer soil moisture products over a half-degree region in Southwestern France. Geophysical Research Letters, 2006, pp.L17401. 10.1029/2006GL027231 . hal-00259755

\section{HAL Id: hal-00259755 \\ https://hal.science/hal-00259755}

Submitted on 29 Feb 2008

HAL is a multi-disciplinary open access archive for the deposit and dissemination of scientific research documents, whether they are published or not. The documents may come from teaching and research institutions in France or abroad, or from public or private research centers.
L'archive ouverte pluridisciplinaire HAL, est destinée au dépôt et à la diffusion de documents scientifiques de niveau recherche, publiés ou non, émanant des établissements d'enseignement et de recherche français ou étrangers, des laboratoires publics ou privés. 
Evaluation of ERS Scatterometer soil moisture products over a half-degree region in Southwestern France

Thierry Pellarin ${ }^{1}$, Jean-Christophe Calvet ${ }^{2}$, Wolfgang Wagner $^{3}$

Abstract- This paper investigates the ERS Scatterometer soil moisture products precision over a half-degree region in Southwestern France. Based on a high resolution soil moisture simulation $\left(1 \mathrm{~km}^{2}\right)$ validated at the local scale, the ERS-scat product is assessed at its own resolution (about $50 \times 50 \mathrm{~km}^{2}$ ). The study points out the suitable quality of the surface soil moisture product (root mean square error equal to $0.06 \mathrm{~m}^{3} \cdot \mathrm{m}^{-3}$ for a 4-year period) and assesses the retrieved root-zone soil moisture accuracy provided by a semi-empirical methodology exclusively based on surface soil moisture products.

\section{Introduction}

Surface soil moisture plays a key role in the water and energy exchanges between the land surface and the atmosphere. Several authors have shown that microwave frequencies (1$10 \mathrm{GHz}$ ) are relevant for soil moisture monitoring. Current sensors are used to provide soil moisture estimates such as the European Space Agency (ESA) sensors ERSScatterometer and ERS-SAR (since 1992), ENVISAT-SAR (since 2002), and the National

\footnotetext{
${ }^{1}$ Laboratoire d'Etude des Transferts en Hydrologie et Environnement, Université de Grenoble, Institut National des Sciences de l'Univers, CNRS, Grenoble, France

${ }^{2}$ Centre National de Recherche Météorologique, Météo-France, Toulouse, France

${ }^{3}$ Institute of Photogrammetry and Remote Sensing, Vienna University of Technology, Vienna, Austria
} 
Aeronautics and Space Administration (NASA) sensors such as the AMSR-E radiometer (since 2002). In near future, soil moisture measurements will also be provided by METOP-ASCAT (2006) and the first satellite specifically dedicated for improving the knowledge of soil water content in the upper surface layer on a global scale : the Soil Moisture and Ocean Salinity (SMOS) mission [Kerr et al., 2001] scheduled for launch in 2007.

Derived soil moisture estimates from satellite sensors are mainly confronted to two main difficulties. First, the validation problem due to the coarse spatial resolution which is about 50x50 km² (ERS-Scat, AMRS-E, METOP-ASCAT, SMOS). Several studies were devoted to assess the retrieval error using indirect approaches over different environments, e.g. Wagner et al. [1999ab] who used meteorological observations or Drusch et al. [2004] who used operational products. A direct quantitative estimation of the retrieval error requires a large amount of in-situ soil moisture measurements over a $50 \times 50 \mathrm{~km}^{2}$ area such as in the study of Ceballos et al. [2005] in the Iberian Peninsula (20 in-situ soil moisture measurements). Presently, apart from a small number of regions worldwide, no extensive ground measurements of soil moisture exist to quantitatively assess the retrieval error. Second, active and passive microwaves measurements are only sensitive to the first centimetres of the surface layer whereas most applications use the root-zone soil moisture $(0.5 \mathrm{~m}$ to a few meters depending on soil type and bioclimatic conditions).

In the present study, both difficulties related to the use of soil moisture satellite observations were discussed. A high resolution $\left(1 \mathrm{~km}^{2}\right)$ synthetic soil moisture data set over a $40 \mathrm{x} 40 \mathrm{~km}^{2}$ area in Southwestern (SW) France was used to assess the two ERS-scat 
soil moisture products (surface soil moisture and root-zone soil moisture) of the Vienna University of Technology [Wagner et al., 2003]. Section II is devoted to describe the study area and to validate soil moisture simulations as well as ERS-scat near-surface soil moisture observations. Section III presents the methodology to provide root-zone soil moisture from surface soil moisture time-series. Then, Section IV is devoted to compare the root-zone soil moisture ERS-scat products with high resolution soil moisture simulations.

\section{Study area and data validation}

\section{$2.1 \quad$ A $40 \times 40 \mathrm{~km}^{2}$ region in SW France with soil moisture field observations}

A $40 \times 40 \mathrm{~km}^{2}$ area was selected in SW France, close to the Les-Landes forest because ground soil moisture data were available for 1986 (Hapex-Mobilhy). The geographic coordinates of the centre of the pixel are: $0.045 \mathrm{E}, 43.86 \mathrm{~N}$. The most important fraction of the pixel is composed of annual crops (77\%), the rest is composed of vineyards $(6.2$ $\%)$, grasslands $(7.2 \%)$ and forests $(9.6 \%)$. A detailed description of soil and vegetation characteristics is available at $1 \mathrm{~km}$ resolution, based on ECOCLIMAP, a surface parameter database derived from land cover and climatic maps [Masson et al., 2003]. This classification distinguishes 7 different land covers over the selected area.

The considered pixel is rather heterogeneous and displays strong East-West gradients of vegetation cover and precipitation (the Eastern part of the pixel is wetter). Also, large differences of soil texture are observed in this region.

The Hapex-Mobilhy experiment [André et al., 1986] goals were to measure and to simulate the energy and water budget over a $14500 \mathrm{~km}^{2}$ region in SW France in order to 
develop and validate the now operational land surface scheme of Météo-France known as Interaction between Soil Biosphere and Atmosphere (ISBA) [Noilhan and Planton, 1989]. During this experiment a ground network was implemented: 14 soil moisture measurement sites, 12 surface flux stations and 33 gauging stations, during 1986 and part of 1987 [Goutorbe et al., 1989]. Four soil moisture Hapex-Mobilhy sites are within the $40 \times 40 \mathrm{~km}^{2}$ selected area: Caumont $\left(43^{\circ} 41 \mathrm{~N}, 0^{\circ} 06 \mathrm{~W}\right)$, Courrensan $\left(43^{\circ} 49 \mathrm{~N}, 0^{\circ} 16 \mathrm{E}\right)$, Fusterouau $\left(43^{\circ} 42 \mathrm{~N}, 0^{\circ} 01 \mathrm{~W}\right)$ and Lagrange $\left(43^{\circ} 58 \mathrm{~N}, 0^{\circ} 03 \mathrm{~W}\right)$. Two of them (Caumont and Courrensan) are non-irrigated sites.

\subsection{The ISBA-A-g 10 -year simulation}

The ISBA surface scheme [Noilhan and Planton, 1989] is based on the equations of the force-restore method [Deardorff, 1978]. This scheme has been developed for both operational forecast and climate modelling requirements. The Hapex-Mobilhy experiment provided the initial database for ISBA development and leaded to successive improvements of the surface scheme [Mahfouf and Noilhan, 1996, Noilhan and Mahfouf, 1996, Boone et al., 2000]. Since Hapex-Mobilhy, numerous experiments were undertaken over various ecosystems and ISBA surface scheme performed well in intercomparison projets such PILPS2c [Wood et al., 1998] or PILPS2d [Slater et al., 2001]. In order to improve the representation of the vegetation in ISBA, Calvet et al. [1998] proposed a $\mathrm{CO}_{2}$-responsive version of ISBA, called ISBA-A-gs. In ISBA-A-gs the stomatal conductance is driven by photosynthesis, following the approach of [Jacobs 1994]. The accumulated net assimilation of $\mathrm{CO}_{2}$, is used by the model to simulate the leaf biomass

and the leaf area index (LAI). The parameters of ISBA-A-gs were adapted for the vegetation types observed in SW France. 
The atmospheric forcing is a continuous, gridded data base derived from the observations provided by the surface network of Météo-France, for a 10 year period (1985-1995). The ISBA-A-gs model was run for each $1 \times 1 \mathrm{~km}^{2}$ grid-point of the $40 \times 40 \mathrm{~km}^{2}$ pixel. Therefore, 1600 simulation series of ten-year were performed. The simulated variables include LAI, surface and root-zone soil moisture.

\subsection{ERS-scat data}

The Scatterometer onboard the ERS-1 satellite, operated by the ESA, regularly acquired data between August 1991 and May 1996. The instrument operates at $5.3 \mathrm{GHz}$ (C-band) vertical polarization, and has three antennas collecting backscatter measurements over incidence angles ranging between $18^{\circ}$ and $59^{\circ}$ at the surface. The spatial resolution is 50 $\mathrm{km}$ at approximately 10:30 and 23:00 local time for ascending and descending tracks, respectively.

The backscattering signal is principally influenced by surface soil moisture, vegetation and soil roughness effects. Several studies were devoted to retrieve vegetation parameter using ERS Scatterometer data [Frison and Mougin 1996; Jarlan et al. 2003; Frison et al. 1998]. Other studies have shown the sensitivity of the ERS Scatterometer to soil moisture over different regions [Wagner and Scipal 2000, Woodhouse and Hoekman 2000, Ceballos et al. 2005]. Finally, authors investigated the way to separate soil moisture from surface roughness and vegetation effects [Magagi and Kerr, 2001].

In this study, the methodology used to extract surface soil moisture from the backscattered coefficient is based on the change detection method, such as suggested by Dobson and Ulaby [1986]. The methodology is described in Wagner et al. [1999ab], which exploits the information provided by the multiple incidence angle measurements acquired by the 
ERS scatterometer. The change detection method allows discriminating between variable processes (soil moisture, vegetation) and invariant processes (surface roughness). Thus, considering a nine-year measurement period (1992 to 2000), it is assumed that the minimum and the maximum extracted backscattered values represent completely dry and saturated surface soil conditions, respectively, over the considered area. Therefore, the retrieved surface soil moisture status is represented by a saturation index which can take values between 0 and 1 .

\subsection{Validation of ISBA root-zone soil moisture using field observations}

The Soil Wetness Index (SWeI) is generally used to describe the relative plant extractable soil moisture, between the wilting point $(\mathrm{SWeI}=0)$ and the field capacity $(\mathrm{SWeI}=1)$. The formulation of the SWeI is given by :

$$
S W e I=\frac{w_{2}-w_{w i l t}}{w_{f c}-w_{w i l t}}
$$

where $w_{2}$ is the modelled root-zone soil moisture, $w_{\text {wilt }}$ is the wilting point and $w_{f c}$ is the field capacity (in ISBA, both values depend on the fraction of clay).

Two SWeI comparisons were conducted on the Caumont and the Courrensan sites (the two others are irrigated sites and irrigation is not accounted for in this version of ISBA-Ags). Soil moisture measurements were archived every $10 \mathrm{~cm}$ from $5 \mathrm{~cm}$ to $155 \mathrm{~cm}$ depth. The root zone soil moisture $\mathrm{w}_{2}$ (eq.1) represents the mean value along the profile. The results are shown in Fig. 1. A good agreement is observed between simulated and 
observed root-zone soil moisture over both sites. The efficiency score ${ }^{4}$ (or Nash criterion [Nash and Sutcliffe, 1970]) and the correlation coefficient are greater than 0.86 for both sites and the RMS errors are equal to 0.155 and 0.123 respectively. These results are consistent with a previous study where ISBA simulations were performed during the Hapex-Mobilhy experiment [Habets et al., 1999].

\subsection{Validation of ERS Scatterometer surface soil moisture}

In order to compare the ERS-scat derived surface soil moisture indices ( $m s^{01}$ ranging from 0 to 1$)$ to our continuous simulations, the ERS-scat indices were converted to physical units of $\mathrm{m}^{3} \cdot \mathrm{m}^{-3}$ by using the $90 \%$ confidence interval of the ISBA simulations. The following procedure was used:

$$
m s^{s c a t}=m s^{01}\left[i n t^{+} 90 \%\left(m s^{i s b a}\right)-i n t^{-} 90 \%\left(m s^{i s b a}\right)\right]+i n t^{-9} 90 \%\left(m s^{i s b a}\right)
$$

with

$$
\begin{aligned}
& \text { int }^{+} 90 \%\left(m s^{i s b a}\right)=\mu\left(m s^{i s b a}\right)+1.64 * \sigma\left(m s^{i s b a}\right)=0.334 \mathrm{~m}^{3} \cdot \mathrm{m}^{-3} \\
& \text { int }^{-} 90 \%\left(m s^{i s b a}\right)=\mu\left(m s^{i s b a}\right)-1.64 * \sigma\left(m s^{i s b a}\right)=0.111 \mathrm{~m}^{3} \cdot \mathrm{m}^{-3}
\end{aligned}
$$

where $\mu\left(m s^{i s b a}\right)$ and $\sigma\left(m s^{i s b a}\right)$ are respectively the mean and the standard deviation of the ISBA surface soil moisture, and $m s^{01}$ the ERS-scat degree of saturation (ranging from 0 to 1). For a Gaussian distribution, the $90 \%$ confidence interval is equal to $\mu \pm 1.64 * \sigma$. Figure 2 presents the comparison between simulated and observed normalized surface soil moisture during a 4-year period. The analysis of the two time-series leads to values of correlation coefficient $\left(\mathrm{R}^{2}\right)$, efficiency score, RMS error, and mean bias, equal to 0.34,

\footnotetext{
${ }^{4}$ The efficiency score was developed to compare two time-series in hydrology. It takes values between 1 (perfect fit) and $-\infty$. An efficiency score equal to 0 means that the predicted time-series gives as much information as a constant average observed value.
} 
$0.24,0.061 \mathrm{~m}^{3} \mathrm{~m}^{-3}$ and $0.01 \mathrm{~m}^{3} \cdot \mathrm{m}^{-3}$, respectively. It can be noted that changing the confidence interval to $80 \%$ or $90 \%$ leads to a RMS error equal to 0.058 and $0.066 \mathrm{~m}^{3} \cdot \mathrm{m}^{-3}$ respectively instead of $0.061 \mathrm{~m}^{3} \cdot \mathrm{m}^{-3}$. As a comparison, the RMS error of SMOS surface soil moisture product over crop regions is expected to be close to $0.04 \mathrm{~m}^{3} \cdot \mathrm{m}^{-3}$ [Kerr et al., 2001]. Despite the estimate of the ERS-scat error is higher than what is expected for SMOS, the rather low error we obtain shows that the ERS-scat products permit to monitor surface soil moisture.

\section{Root-zone soil moisture derivation}

Active and passive microwaves are sensitive to the first centimetres of the surface layer (depending on the wavelength and soil moisture), only. However, most applications use the root-zone soil moisture. Several approaches have been developed in order to obtain profile soil moisture estimates based on surface soil moisture information. These approaches are based on regression equations [Ragab, 1995; Biswas and Dasgupta, 1995; Arya et al., 1983; Jackson et al., 1987; Srivastava et al., 1997], inversion approaches [Njoku and Kong, 1977; Entekhabi et al., 1993, 1994], or assimilation methods using surface schemes [Calvet and Noilhan, 2000; Wigneron et al., 1999; Crow and Wood, 2002].

In order to provide global root-zone soil moisture estimates using ERS-scat measurements, Wagner et al. [1999b] proposed a semi-empirical modelling approach which relates a series of surface soil moisture $\left(m s^{01}\right)$ values to the Soil Water Index (SWI) using the following expression: 


$$
S W I(t)=\frac{\sum_{i} m s^{01}\left(t_{i}\right) e^{-\frac{t-t_{i}}{T}}}{\sum_{i} e^{-\frac{t-t_{i}}{T}}}
$$

At time $t$, all measurements taken within a period $[t, t-3 T]$ are considered if at least 4 measurements have been recorded within the most recent time period $[t, t-T]$. The parameter $T$, called the characteristic time length, represents the time scale of soil moisture variations in units of time. Based on ERS-scat measurements, global SWI estimation using the Wagner's methodology can be viewed on the website: http://www.ipf.tuwien.ac.at/radar [Scipal et al., 2002].

It can be noted that the Soil Water Index (SWI) formulation (Eq.3) is slightly different from the Soil Wetness Index (SWeI) formulation (Eq.1) since SWI may take on values between 0 (representing dry conditions) and 1 (representing wet conditions) whereas SWeI may take on values lower than 0 (i.e. below wilting point values) and greater than 1 (i.e. above field capacity values). Wagner et al. [1999b] indicated that SWI $=1$ is representative of an intermediate soil moisture value, between field capacity and total water capacity. In order to compare the ISBA- $A-g_{s}$ root-zone soil moisture simulations (SWeI) with the SWI derived from ERS-scat measurements, a normalization between 0 and 1 of the SWeI was performed.

\section{Statistical analysis}

Figure 3a illustrates the SWI comparison between the continuous ISBA- $A-g_{s}$ simulation and the semi-empirical methodology of Wagner during the four-year period (1991-1995). The T parameter of (Eq.3) was optimized in order to fit the reference SWI curve in terms 
of efficiency score over a 1-year period (dash-dotted line in Fig. 3a from September 1993 to September 1994). The best T value was found to be 32 days (d). The efficiency score is equal to 0.27 and the RMS error is equal to 0.198. Although the general behaviour of the two SWI is similar, some strong differences can be observed. In 1992, the Springtime values are clearly underestimated (SWI $=0.4$ instead of 0.7 ) whereas the Summertime values are highly overestimated $(\mathrm{SWI}=0.6$ instead of 0.2$)$. A similar behaviour can be observed in Spring 1993.

A sensitivity study was performed in order to quantify the respective effect of the noise level and the sampling time on the error on the retrieved SWI. For the rest of the study, we applied a Gaussian noise to the reference ISBA-A-gs surface soil moisture $\left(m s^{i s b a}\right)$ and used the result as input of (Eq.3) for different sampling times. For example, a sampling time of 1 measurement every 3 days (at $10 \mathrm{~h} 30 \mathrm{am}$ ) and a Gaussian noise level of 0.04 $\mathrm{m}^{3} \mathrm{~m}^{-3}$ (similar to the SMOS expected configuration) is applied to $m s^{i s b a}$. The retrieved SWI is plotted in Fig. 3b. The efficiency score is equal to 0.65 and the RMS error is equal to 0.17 . The best $\mathrm{T}$ parameter, in this case, is $20 \mathrm{~d}$. Similar to Fig. 3a, a large mismatch can be observed during Springs 1992 and 1993 where the retrieved SWI is slightly underestimated. Frozen soil periods were found to be responsible for the Springtime underestimations of the root-zone soil moisture by the Wagner's methodology. A short soil freezing event appears like a sudden dry value of the surface soil moisture which is wrongly exploited in the root-zone calculation of Eq. 3. This constitutes a limitation of the methodology because just based on the scatterometer data alone it is not possible to identify frozen soil conditions. Figure $3 b$ indicates frozen soil periods (vertical grey lines) which are often followed by a sudden unrealistic decrease of the root-zone soil moisture 
retrieval. A verification of this assumption is proposed in Fig. 3c where the addition of both the liquid and the solid (iced) part of the surface soil moisture was used as input of Eq. 3. The retrieved SWI is clearly improved particularly during frozen soil periods (efficiency score equal to 0.73 instead of 0.65 ).

A systematic sensitivity study was performed for a range of noise levels (from 0 to 0.08 $\mathrm{m}^{3} \mathrm{~m}^{-3}$ ) and a range of sampling times ( 1 measurement every 1 to $\left.19 \mathrm{~d}\right)$. The results of the sensitivity study are presented in Fig. 4. The effect of both the noise level and the sampling time can be observed in this graph in terms of efficiency score ${ }^{5}$. As expected, it can be noted that the accuracy of the retrieved SWI is decreasing as the noise level and the sampling time increase. Considering that an efficiency score equal to 0.6 is suitable, the sampling time should be of 1 measurement every day for a noise level of $0.06 \mathrm{~m}^{3} \mathrm{~m}^{-3}$ whereas 1 measurement every 3 day is sufficient for a noise level of $0.04 \mathrm{~m}^{3} \mathrm{~m}^{-3}$. The ERS-scat mean time sampling was considered to be 6 days given that 240 measurements were obtained during the 4-year period. The low value of the efficiency score $(0.27)$ may be due to the irregular time sampling of ERS-scat which leads to lower SWI retrieval accuracy than a regular 6-days time sampling.

\section{Conclusions}

A 10-year simulation was performed over 1600 square-kilometre pixels, representing a $40 \times 40 \mathrm{~km}^{2}$ area in SW France. Results were compared with the 50x50 $\mathrm{km}^{2}$ ERS-scat surface soil moisture and root-zone soil moisture products. A good agreement was found

\footnotetext{
${ }^{5}$ Each efficiency score value is a mean value of 50 runs using the same noise level and time sampling but with a different random noise
} 
between the ERS-scat surface soil moisture product and the averaged surface soil moisture values obtained with the ISBA-A-gs model over the 1600 pixels. The RMS error was found to be equal to $0.061 \mathrm{~m}^{3} \mathrm{~m}^{-3}$, which is larger than the expected SMOS accuracy over crop fields $\left(0.04 \mathrm{~m}^{3} \mathrm{~m}^{-3}\right)$ but can be considered as an acceptable accuracy. The rootzone soil moisture product based on a semi-empirical modelling approach proposed by Wagner et al. [1999b] was analysed. The accuracy of the methodology was found to be dependant on the time sampling mode, the error on the surface soil moisture estimates and the presence of frozen soil conditions. First, it was shown that an irregular time sampling mode may leads to lower SWI retrieval accuracy than a regular time sampling mode (considering an identical number of surface soil moisture measurements during a 4-year period). Second, a sensitivity study described quantitatively the effect of the surface soil moisture noise level on the root-zone soil moisture estimates. Third, the effect of frozen soil was shown to be a potential source of erroneous root-zone soil moisture retrievals. The Wagner's methodology should be used together with a soil freezing detection procedure in order to not take into account frozen surface soil moisture estimates in the retrieval algorithm.

This study pointed out the potential of scatterometer measurements for soil moisture monitoring as well as Wagner's methodology for root-zone soil moisture estimates. In the near future, the regular 2-day time sampling of the METOP-ASCAT Mission (ESA, launch in July, 2006) and the 2-day time sampling of the SMOS Mission (ESA, launch in September 2007) should provide better root-zone soil moisture products (efficiency score equal to 0.65 for a RMS error equal to $0.04 \mathrm{~m}^{3} \cdot \mathrm{m}^{-3}$ in our simulations). 


\section{References}

André J.C., J.P. Goutorbe, A. Perrier (1986), HAPEX-MOBILHY : A hydrologic atmospheric experiment for the study of water budget and evaporation flux at the climate scale, Bull. Amer. Meteor. Soc., 67, 138144.

Arya, L. M., J. C.Richter, and J. F. Paris (1983), Estimating Profile Water Storage from Surface Zone Soil Moisture Measurements Under Bare Field Conditions. Water Resour. Res., 19(2): 403-412.

Biswas, B. C., and S. K. Dasgupta (1979), Estimation of Soil Moisture at Deeper Depth from Surface Layer Data. Mausam, 30(4): 511-516.

Boone A., V. Masson, T. Meyers T and J. Noilhan (2000), The influence of the inclusion of soil freezing on simulations by a soil-vegetation-atmosphere transfer scheme, Journal of Applied Meteorology, 39 (9): 1544-1569

Calvet, J.-C., J. Noilhan, J.-L. Roujean, P. Bessemoulin, M. Cabelguenne, A. Olioso and J.-P. Wigneron (1998), An interactive vegetation SVAT model tested against data from six contrasting sites, Agricultural and Forest Meteorology, 92, 73-95.

Calvet, J.-C. (2000), Investigating soil and atmospheric plant water stress using physiological and meteorological data, Agricultural and Forest Meteorology, 103, 229-247.

Calvet, J.-C. and J. Noilhan (2000), From near surface to root-zone soil moisture using year-round data, Journal of hydrometeorology, 1, (5), 393-411.

Ceballos, A., K. Scipal, W. Wagner, and J. Martinez-Fernandez (2005), Validation of ERS Scatterometerderived soil moisture data in the central part of the Duero Basin, Spain, Hydrological Processes, 19 (8), 1549-1566.

Crow W.T., and E.F. Wood (2002), The assimilation of remotely sensed soil brightness temperature into a land surface model using Ensemble Kalman filtering: A case study based on ESTAR measurements during SGP97. Advances in Water Resources 26, 137-149.

Deardorff J.W. (1978), Efficient prediction of ground temperature and moisture with inclusion of a layer of vegetation, Journal of Geophysical research, 83, 1889-1903. 
Dobson M. C. and F. T. Ulaby (1998), Mapping soil moisture distributions with imaging radar, Principles and Applications of Imaging Radars, Manual of Remote Sensing, F. M. Henderson and A. J. Lewis, Eds. New York: Wiley, 407-433.

Drusch, M., E. F. Wood, and H. Gao, A. Thiele (2004), Soil moisture retrieval during the Southern Great Plains Hydrologic Experiment 1999: A comparison between experimental remote sensing data and operational products, Water Resources Research 40, W02504, doi:10.1029/2003WR002441.

Entekhabi, D., H. Nakamura and E.G. Njoku (1993), Retrieval of Soil Moisture by Combined Remote Sensing and Modeling. In: Choudhury, B. J., Kerr, Y. H., Njoku, E. G., and Pampaloni, P. (Eds.), ESA/NASA International Workshop on Passive Microwave Remote Sensing Research Related to LandAtmosphere Interactions, St. Lary, France, 485-498.

Entekhabi, D., H. Nakamura and E.G. Njoku (1994), Solving the Inverse Problem for Soil Moisture and Temperature Profiles by Sequential Assimilation of Multifrequency Remotely Sensed Observations. IEEE Trans. Geosci. Rem. Sens., 32(2): 438-448.

Frison P. -L., E. Mougin, and P. Hiernaux (1998), Observation and interpretation of seasonal ERS-1 Wind Scatterometer data over northern Sahel (Mali), Remote Sens. Environ., 63, 233-242.

Frison P.-L. and E. Mougin (1996), Use of ERS-1 wind scatterometer data over land surfaces. IEEE Trans. Geosci. Remote Sensing, 34, (2), 550-560.

Goutorbe J.-P., J. Noilhan, C. Valancogne, R. H. Cuenca, 1989. Soil moisture variations during HAPEXMOBILHY. Ann. Geophys. 7 (4), 415-426.

Habets F., J. Noilhan, C. Golaz, J.-P. Goutorbe, P. Lacarrère, E. Leblois, E. Ledoux, E. Martin, C. Ottlé, and D. Vidal-Madjar (1999), The ISBA surface scheme in a macroscale hydrological model applied to the Hapex-Mobilhy area. Part II: Simulation of steamflows and annual water budget, Journal of Hydrology, $217,97-118$

Jackson, T. J., Hawley, M. E., and O’Neill, P. E. (1987), Preplanting Soil Moisture Using Passive Microwave Sensors. Water Resources Bulletin, 23(1): 11-19.

Jacobs, C.M.J. (1994), Direct impact of atmospheric $\mathrm{CO}_{2}$ enrichment on regional transpiration, Ph.D. Thesis, Agricultural University, Wageningen, 179 p. 
Jarlan L., P. Mazzega, E. Mougin, F. Lavenu, G. Marty, P.L. Frison, and P. Hiernaux (2003), Mapping of Sahelian vegetation parameters from ERS scatterometer data with an evolution strategies algorithm. Remote Sensing of Environment, 87, (1), 72-84.

Kerr Y. H., P. Waldteufel, J.-P. Wigneron, J. M. Martinuzzi, J. Font, and M. Berger (2001), Soil moisture retrieval from space: The Soil Moisture and Ocean Salinity (SMOS) mission, IEEE Trans. Geosci. Remote Sensing, 39, (8), 1729-1735.

Magagi RD, and Kerr YH (2001), Estimating surface soil moisture and soil roughness over semiarid areas from the use of the copolarization ratio, Remote Sensing of Environment 75 (3): 432-445.

Mahfouf J.F. and J. Noilhan (1996), Inclusion of gravitational drainage in a land surface scheme based on the force-restore method, Journal of Applied Meteorology, 35 (6): 987-992.

Masson V., J.L. Champeaux, F. Chauvin, C. Meriguet, and R. Lacaze (2003), A global database of land surface parameters at 1-km resolution in meteorological and climate models, J. Climate, 16 (9), 12611282.

Nash J. E., and J. V. Sutcliffe (1970), River flow forecasting through conceptual models, discussion and principles, J.Hydrol., 10, 282-290.

Njoku, E. G., and Kong, J. A. (1977), Theory for Passive Microwave Remote Sensing of Near-Surface Soil Moisture. J. Geophys. Res., 82(20): 3108-3118.

Noilhan J. and J.F. Mahfouf (1996), The ISBA land surface parameterisation scheme, Global and Planetary Change 13 (1-4): 145-159.

Noilhan, J. and S. Planton (1989), A simple parameterization of land surface processes for meteorological models, Mon. Wea. Rev., 117, 536-549.

Ragab, R. (1995), Towards a Continuous Operational system to Estimate the Root-Zone Soil Moisture from Intermittent Remotely Sensed Surface Moisture. J. Hydrol., 173: 1-25.

Scipal K, W. Wagner, M. Trommler, and K. Naumann (2002), The Global Soil Moisture Archive 19922000 from ERS Scatterometer Data: First Results. In Proc. IGARRS'2002, Toronto, Canada, 24-28 June 2002, CD-ROM.

Slater A.G. and 33 co-authors (2001), The representation of snow in land surface schemes: Results from PILPS 2(d), journal of hydrometeorology 2 (1): 7-25. 
Srivastava, S. K., N. Yograjan, V. Jayaraman, P.P. Nageswara Rao, and M.G. Chandrasekhar (1997), On the Relationship Between ERS-1 SAR/Backscatter and Surface/Sub-Surface Soil Moisture Variations in Vertisols. Acta Astronautica, 40(10): 693-699.

Wagner W, J. Noll, M. Borgeaud, and H. Rott (1999a), Monitoring Soil Moisture over the Canadian Prairies with the ERS Scatterometer. IEEE Transactions on Geoscience and Remote Sensing 37(1): 206-216.

Wagner W, G. Lemoine, and H. Rott (1999b), A method for estimating soil moisture from ERS Scatterometer and soil data. Remote Sensing of Enviroment 70, 191-207.

Wagner W., K. Scipal, C. Pathe, D. Gerten, W. Lucht, and B. Rudolf (2003), Evaluation of the agreement between the first global remotely sensed soil moisture data with model and precipitation data, Journal of Geophysical Research - Atmospheres, 108(D19), 4611, doi: 10.1029/2003JD003663.

Wigneron JP, A. Olioso, J.C. Calvet, and P. Bertuzzi (1999), Estimating root zone soil moisture from surface soil moisture data and soil-vegetation-atmosphere transfer modelling. Water Research Resources 35: 3735-3745.

Wood E.F. and 28 co-authors (1998), The Project for Intercomparison of Land-surface Parameterization Schemes (PILPS) Phase 2(c) Red Arkansas River basin experiment: 1. Experiment description and summary intercomparisons, Global and Planetary Change, Vol. 19, Issues 1-4 , 115-135.

Woodhouse I. H. and D. H. Hoekmann (1998), The retrieval of regional scale geophysical parameters in semi-arid areas using data from the ERS Windscatterometer, Proc. Joint Eur. Space Agency-Eumetsat Workshop on Emerging Scatterometer Applications-From Research to Operations, Noordwijk, The Netherlands, Oct. 5-7. 

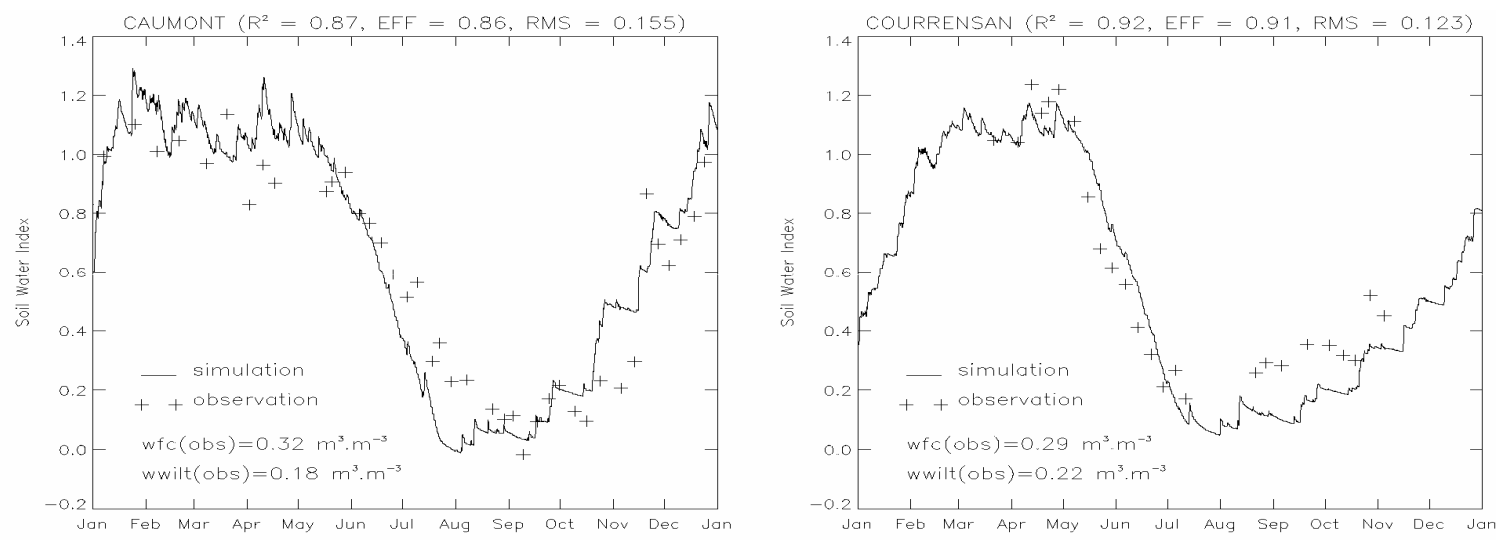

Figure 1: Soil Wetness Index (SWeI) observed by neutron soundings (+) and simulated over the corresponding grid-cell of Caumont and Courrensan (-) during 1986. 


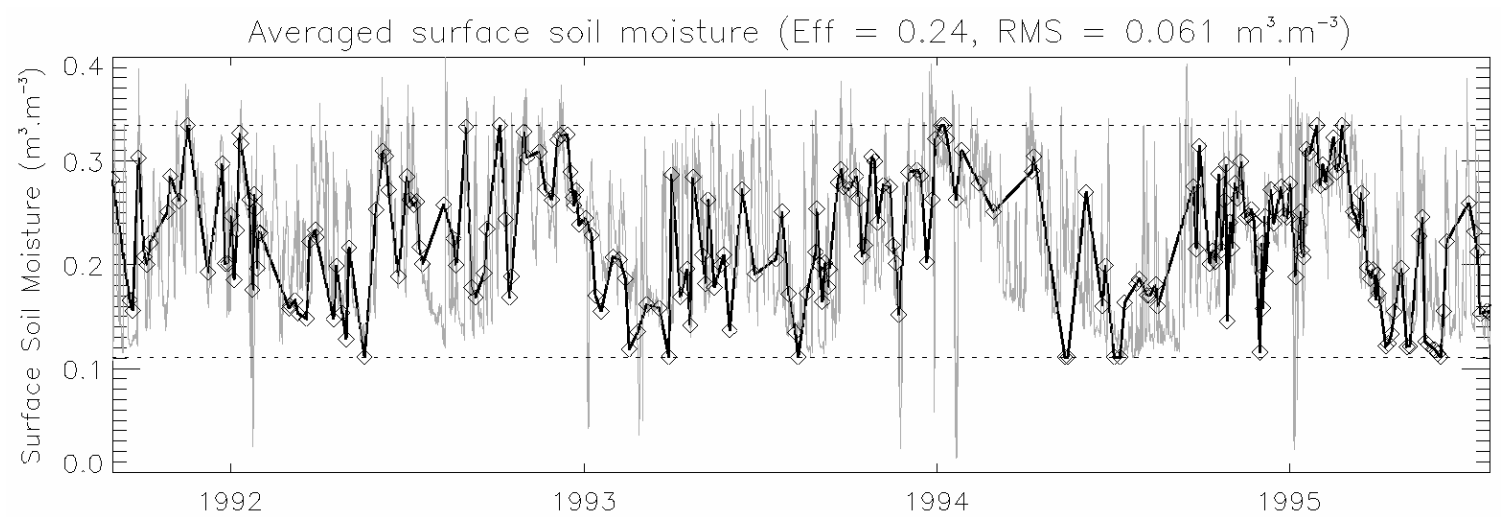

Figure 2: ISBA simulated surface soil moisture time-series averaged over the 1600 pixels (grey curve) and ERS scatterometer-derived surface soil moisture from August 1991 to July 1995 (diamonds and black curve). The variation range of ERS-scat surface soil moisture measurements has been delimited using $90 \%$ confidence interval values (dotted line) of ISBA-A-gs simulation. 

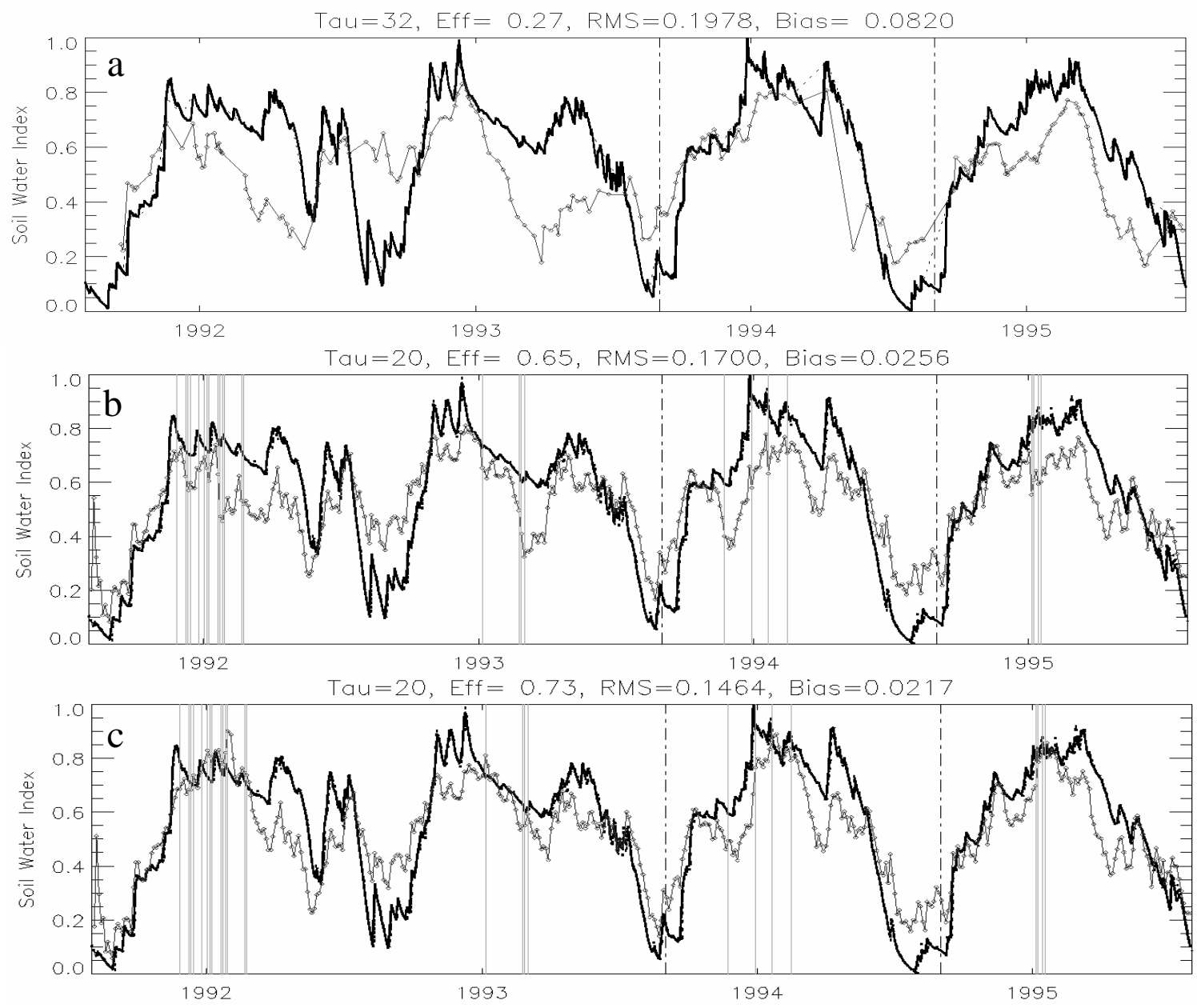

Figure 3: (a) Reference Soil Water Index (black curve) and SWI estimate (diamonds grey curve) based on ERS-scat surface soil moisture measurements and (Eq.3). The T parameter of (Eq.3) was optimized $(\mathrm{T}=32 \mathrm{~d})$. (b) SWI estimate (diamonds curve) obtained by using the ISBA-A-gs' simulated surface soil moisture noised with a Gaussian noise level of $0.04 \mathrm{~m}^{3} \mathrm{~m}^{-3}$ and one value every 3 day $(10 \mathrm{~h} 30 \mathrm{am})$. The $\mathrm{T}$ parameter of (Eq.3) was optimized ( $\mathrm{T}=20 \mathrm{~d}$ ). Vertical grey solid lines correspond to soil freezing days. (c) Same as (b) but using the addition of iced and liquid part of surface soil moisture provided by ISBA-A-gs as input of Eq. 3. 


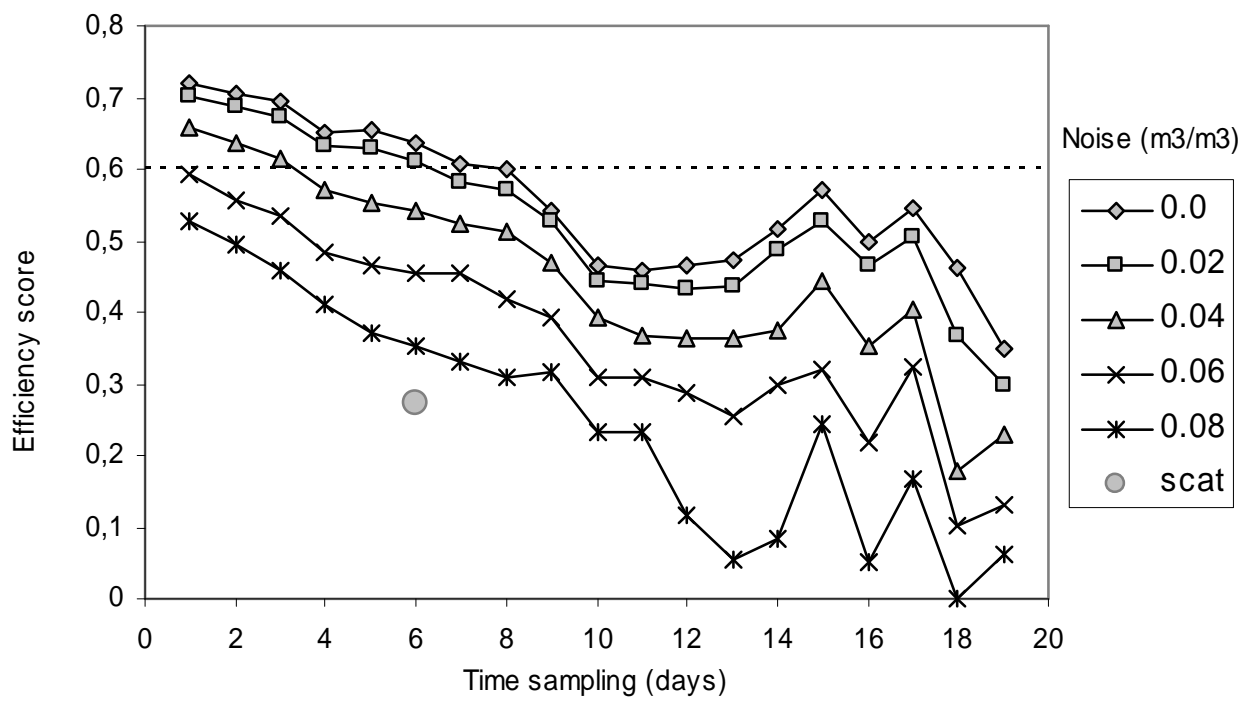

Figure 4: Time sampling and noise level effect on the retrieved root-zone soil moisture in terms of efficiency. The root-zone soil moisture retrieval using ERS-scat measurements is plotted with a closed circle (efficiency=0.27) and assumed to be a 6-day time sampling (240 measurements during 4 years corresponds to 1 measurement every 6 days in average). 